Letter

\title{
Prospects for Detecting Volcanic Events with Microwave Radiometry
}

\author{
Shannon M. MacKenzie (D) and Ralph D. Lorenz (1) \\ Applied Physics Laboratory, Johns Hopkins University, 1001 Johns Hopkins Road, Laurel, MD 20723, USA; \\ Ralph.Lorenz@jhuapl.edu \\ * Correspondence: shannon.mackenzie@jhuapl.edu
}

Received: 17 June 2020; Accepted: 5 August 2020; Published: 7 August 2020

\begin{abstract}
Identifying volcanic activity on worlds with optically thick atmospheres with passive microwave radiometry has been proposed as a means of skirting the atmospheric interference that plagues near infrared observations. By probing deeper into the surface, microwave radiometers may also be sensitive to older flows and thus amenable for investigations where repeat observations are infrequent. In this investigation we explore the feasibility of this tactic using data from the Soil Moisture Active Passive (SMAP) mission in three case studies: the 2018 Kilauea eruption, the 2018 Oct-Nov eruption at Fuego, and the ongoing activity at Erta Ale in Ethiopia. We find that despite SMAP's superior spatial resolution, observing flows that are small fractions of the observing footprint are difficult to detect-even in resampled data products. Furthermore, the absorptivity of the flow, which can be temperature dependent, can limit the depths to which SMAP is sensitive. We thus demonstrate that the lower limit of detectability at L-band $(1.41 \mathrm{GHz})$ is in practice higher than expected from first principles.
\end{abstract}

Keywords: volcanoes, SMAP, microwave radiometry

\section{Introduction}

Volcanism has reshaped the surfaces of planets and moons across the solar system from Mercury (e.g., [1]) to perhaps even Pluto [2]. The introduction of gas and particulates into planetary atmospheres can replenish volatiles [3] or drive climate change (e.g., [4,5]). Monitoring the frequency and style of volcanic events is therefore an important diagnostic for interior and atmospheric processes.

Detecting volcanism, however, can present a challenge for worlds with an optically thick atmosphere like Venus and Titan, even to spacecrafts in orbit. Near infrared observations have the advantage of sampling at or near the peak of the Planck curve; changes in temperature translate to easily-detectable increases in observed radiance. The optical thickness of cloud layers at Venus and Titan, however, limit resolution at these wavelengths [6,7].

The likelihood of detection increases when observing in the microwave where atmospheric interference is minimal and longer wavelengths penetrate deeper into the cooling flow. Flow interiors, after all, cool more slowly than the crustal skin to which IR wavelengths are sensitive. For example, Bondarenko et al. [8] calculated that even 15 year old Venusian flows can be $>100 \mathrm{~K}$ warmer than the near surface temperature if the flow is $30 \mathrm{~m}$ and mafic or ultramafic. Using a similar approach, Lorenz et al. [9] showed that the depending on the loss tangent of hypothetical cryovolcanic flows on Saturn's moon Titan, whose existence and composition are still a matter of debate, the duration of temperature excess at depth in the flow is on the order of days to a few years.

One challenge with microwave radiometry, however, lies in spatial resolution. Lower frequency observations probe deepest and are therefore, in principle, most useful for detecting flows when repeat observations are infrequent. For example, as noted in [10], a Venus mapper in a low orbit may not 
visit a given site for many months, by which time a lava flow may cease to be incandescent at the surface. However, the low energy of longer wavelength passive observations requires larger antennae, and therefore larger fields of view, for sufficient SNR. Titan and Venus have both been explored with microwave radiometry, but the radar investigations of the Cassini and Magellan missions prioritized mapping synthetic aperture radar during closest approach. The spatial resolution of resulting datasets is therefore less than one might expect from the size of the high-gain antennae: $4 \mathrm{~m}$ diameter for Cassini RADAR (13.78 GHz passive Ku-band; Elachi et al. [11]) and $3.7 \mathrm{~m}$ diameter for the Magellan Radar System (2.385 GHz; Saunders et al. [12]). Microwave radiometry at $3.2 \mathrm{GHz}$ with a footprint of $5 \times 30 \mathrm{~km}$ and a radiometric precision of $1 \mathrm{~K}$ is also an intended feature of the proposed EnVision mission to Venus [13]. It is therefore an open question where the balance between penetration depth and spatial resolution lies.

To explore the utility of low frequency microwave radiometry as a method for volcanic activity monitoring, we use data from the Soil Moisture Active Passive (SMAP) mission [14]. The 6 m diameter antenna has a $36 \mathrm{~km}$ wide footprint and repeats surface coverage every 8 days, offering unprecedented spatial and temporal sampling at $1.41 \mathrm{GHz}$. We take advantage of this opportunity to explore the balance between spatial resolution and sensitivity to the depths at which older flows might still radiate.

Here we present a case study of three volcanic eruptions. We first describe the events and the SMAP observations and then discuss the implications for future observations here on the Earth and elsewhere in the solar system.

\section{Data and Methods}

The SMAP project provides a gridded product (L1C) created by resampling overlapping $36 \mathrm{~km}$ footprints with a Backus-Gilbert interpolation scheme [15] to a $9 \mathrm{~km}$ Equal-Area Scalable Earth Grid Version 2.0 (EASE-Grid 2.0). These data are available from 31 March 2015 to at least the date of this work's publication. The interpolation also takes into account the areal fraction of land or sea covered by each gridded element by mapping the $3 \mathrm{~dB}$ footprint center on a static high-resolution land/water mask (though other schemes have also been identified, e.g., Touati et al. [16]). This increased fidelity is important for our application since many volcanoes are located near land/sea boundaries. Previous investigations with lower level SMAP products were unable to discern hotspot activity [10]. SMAP orbits in a sun-synchronous, near polar orbit, observing the surface at two local times on ascending and descending passes, respectively. These passes repeat exactly on a cadence of 8 days, though the frequency of observations for any given point on the ground can be more frequent given the width of the swath, the target area size, and latitude.

Eruption events were identified via MODIS data with the hot-spot detection systems MODVOLC (http:/ / modis.higp.hawaii.edu) [17] and MIROVA (http:/ / www.mirovaweb.it) [18]. With a swath width of $2550 \mathrm{~km}$, MODIS observes the surface of the every 2 days. A summary of the events investigated in this work is given in Table 1.

Table 1. Eruption events considered in this work. Locations are taken from the database maintained by the Smithsonian Institution Global Volcanism Program (https://volcano.si.edu/).

\begin{tabular}{ccc}
\hline Volcano & Location & Dates \\
\hline Erta Ale & $13.6^{\circ} \mathrm{N}, 40.67^{\circ} \mathrm{E}$ & April 2015-January 2020 \\
Kilauea & $19.421^{\circ} \mathrm{N}, 155.287^{\circ} \mathrm{W}$ & April-October 2018 \\
Fuego & $14.473^{\circ} \mathrm{N}, 90.88^{\circ} \mathrm{W}$ & May-November 2018 \\
\hline
\end{tabular}

\section{Results}

\subsection{Erta Ale}

Ethiopia's Erta Ale volcano hosts a 150 m diameter lava lake [19] within the $0.7 \times 1.6 \mathrm{~km}$ elliptical caldera, active since at least the 1960s [19-21] and a useful analog for lava lakes on Io, a volcanically 
active moon of Jupiter [22,23]. The terrain surrounding the volcano is dominated by previous flows, evaporite deposits, and some ephemeral lakes and is generally devoid of vegetation [20]. In addition to the persistent lava lake, several new flow events have been recorded since SMAP's operation, especially during January-May 2017 and April 2018-2019 [24,25].

However, these events are not manifested in the SMAP data. We extracted the gridded elements that cover Erta Ale $(\mathrm{n}=35)$ and determined the maximum observed brightness temperature over an 8 day window (orange line, Figure 1) to average over all observations during a SMAP orbit. Brightness temperatures vary with season as expected, but no anomalous peaks coincide with MODIS observations of excess radiance over the scene average (gray).

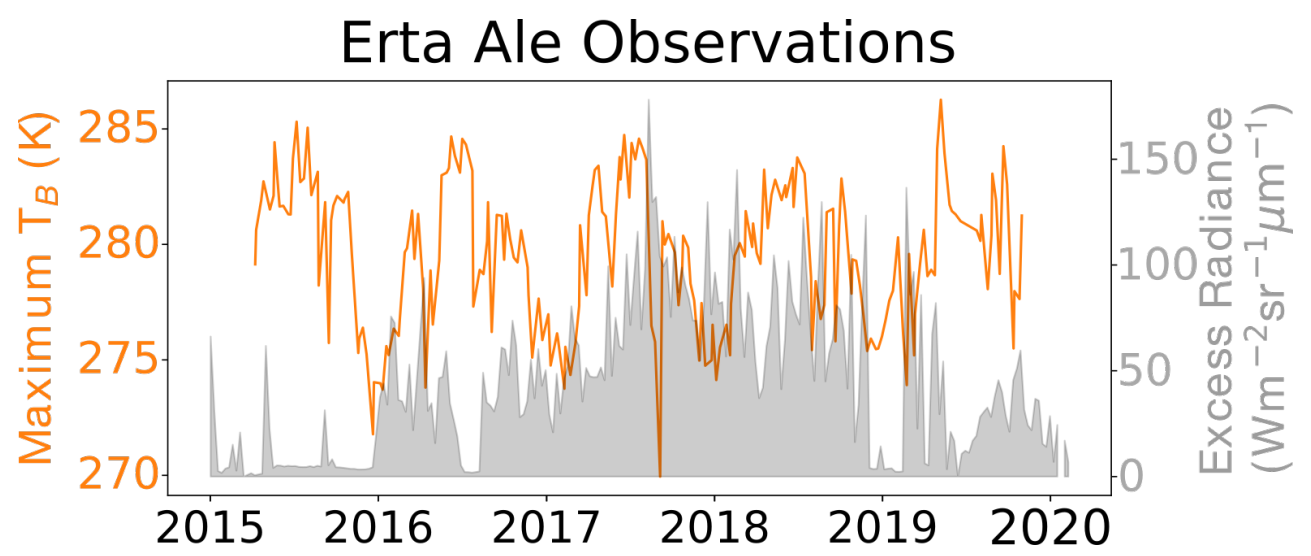

Figure 1. Maximum brightness temperatures observed by Soil Moisture Active Passive (SMAP) (orange) compared to infrared observations by MODIS (gray) [17] for the Erta Ale region. SMAP data are the 35 gridded elements over Erta Ale. Peaks in excess radiance observed by MODIS over the same area do not correlate with anomalously high brightness temperatures (Pearson correlation coefficient $=0.004$ ).

\subsection{Kilauea}

Eruptive events have been observed at the Kilauea East Rift Zone in Hawai'i for at least 200 years, but May-September 2018 saw an unprecedented level of activity, including the collapse of the caldera floor, draining of the lava lake at Halema'uma'u, and the opening of 24 new fissures along the Lower East Rift Zone [26,27]. New fields of lava flows extended several kilometers, running eastward and fanning out at the ocean intercept. Flow thicknesses were typically $20 \mathrm{~m}$ reaching up to $55-280 \mathrm{~m}$ at the edges of the delta. By the end of August 2018, only small hotspots remained (temperatures $>373 \mathrm{~K}$ ) and the total new flow area reached $35 \mathrm{~km}^{2}$ (Figure 2, inset).

In Figure 3 we show the brightness temperatures recorded by SMAP at morning (yellow) and evening (black) observations of the Kilauea Lower East Right Zone. Each plot contains the data for one element of the $9 \times 9 \mathrm{~km}$ EASE2.0 grid (which is outlined in Figure 2). The plots covering a larger fraction of the flows (top right) contain a significant fraction of water, lowering the typical observed brightness temperature. This contamination is corrected for in the $\mathrm{SMAP} \mathrm{T}_{B}$ calibration, resulting in a clear distinction between land- and water-dominated grid elements in Figure 3. Anomalously brightness temperatures appear in June and August in the 6am observations for the entire right column. This is conceivably consistent with the increased area of fresh lava flows, except for the lack of anomalies in July, when sustained levels of volcanic activity were documented [26,27]. Furthermore, the anomalies are also evident in some elements of the grid where the $36 \mathrm{~km}$ footprint does not intersect the flow area (not shown). We therefore do not see obvious evidence of the 2018 Kilauea event in the SMAP data. 


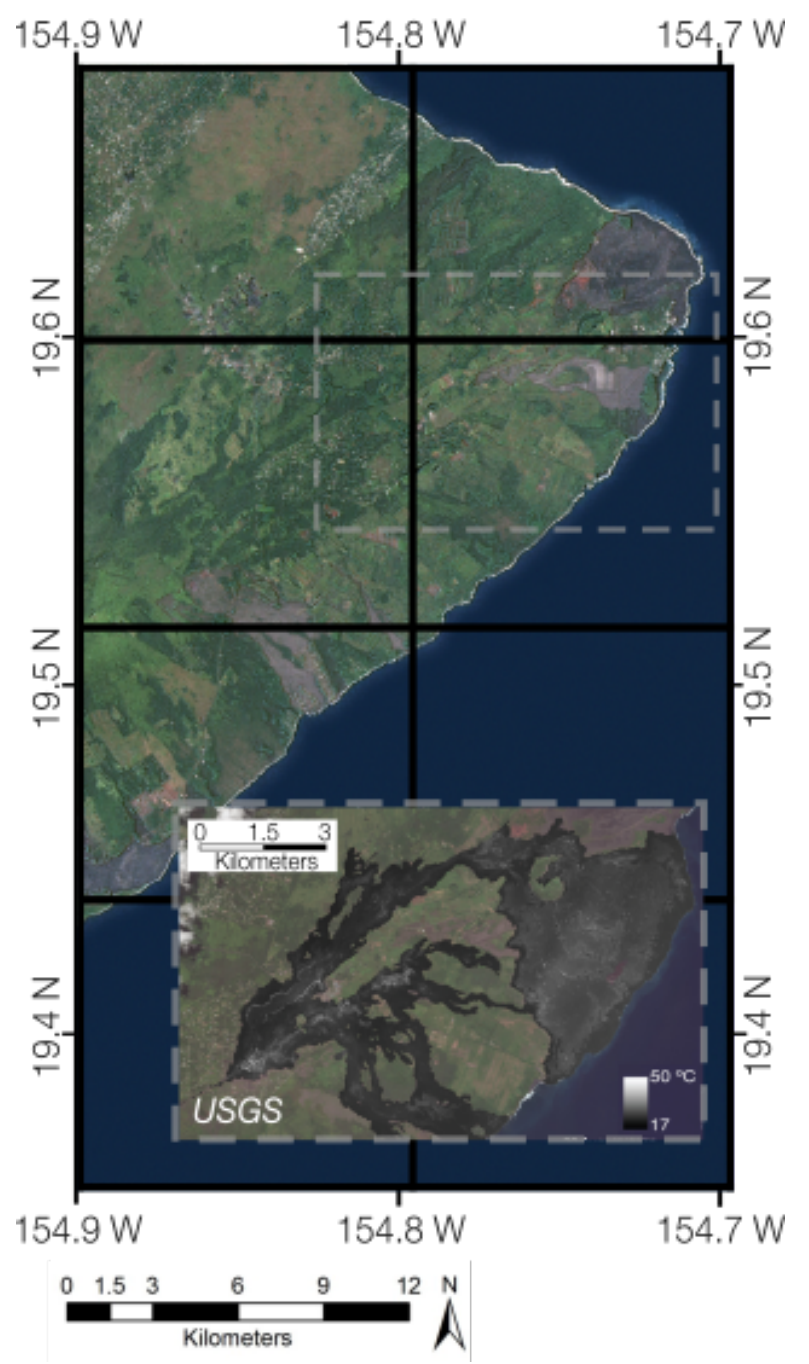

Figure 2. Landsat $15 \mathrm{~m}$ observation of the Kilauea Lower East Rift Zone before the 2018 eruption. Black grid represents the extent of the $9 \mathrm{~km}$ grid to which SMAP data are resampled in L1C products; each plot of Figure 3 represents the time series for each of these bins. Inset image shows thermal activity of the flows on 29 August 2018 (Credit: USGS and DigitalGlobe2019) .

\subsection{Fuego}

The growing frequency of gas emission, minor explosions, and lava flows makes Fuego one of Central America's most active volcanoes [28]. Despite the number of events, however, we cannot search for volcanic activity in the SMAP dataset for the same reason these events often have high fatalities [29]: proximity to population centers. Radio frequency interference (RFI) is mitigated in the SMAP calibration algorithm [30], but some areas experience such high levels of anthropogenic RFI that pockets of data are unusable (Figure 4). For this reason, hotspot events near populous areas-such as Fuego, which is only tens of kilometers from Antigua and the city of Guatemala-are often not detectable with SMAP. 


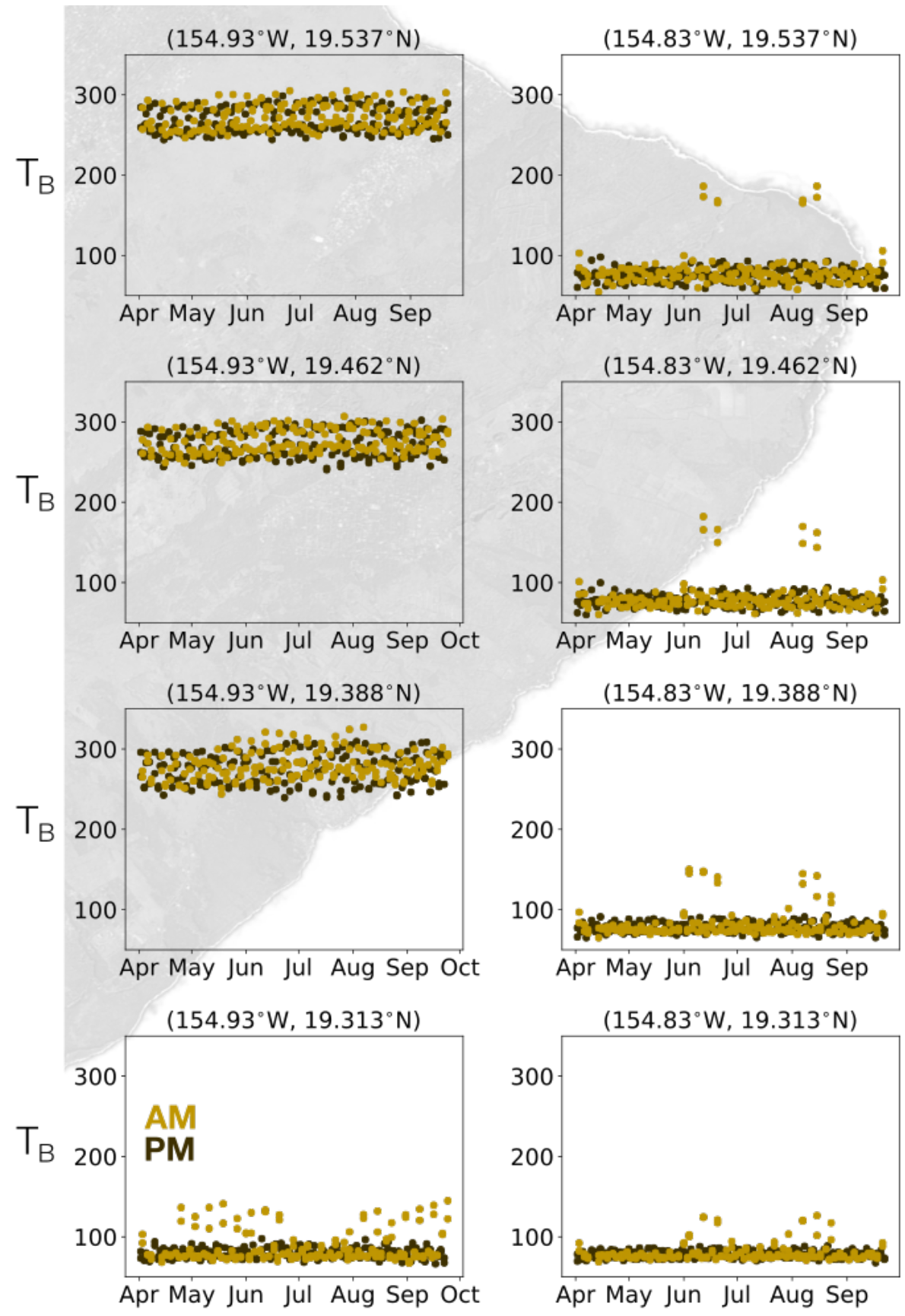

Figure 3. SMAP observations of brightness temperatures of the Kilauea Lower East Rift Zone from April-October 2018. Brightness temperature variations for morning (yellow) and evening (black) track closely, with few anomalies outside the typical variation for land-dominated observations (left column). (SMAP swaths repeat every 8 days, yielding ascending and descending observations every 2 days.) Anomalies in the water-dominated observations (right column) do not correlate with peak flow activity (July). The Landsat image of Figure 2 is shown in grayscale in the background to indicate spatial extent. 


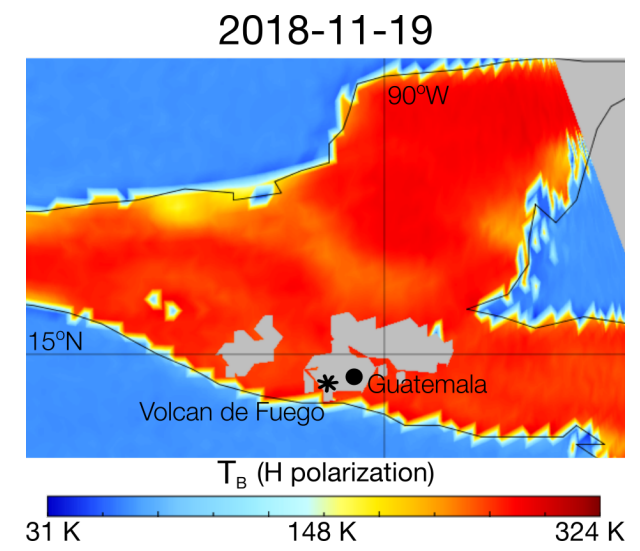

Figure 4. A typical SMAP observation of Central America. Gaps in the L1C data product are the result of mitigation of anthropogenic radio frequency interference (RFI), which increases in heavily populated areas. Presumably, anthropogenic RFI will not be a problem on other planets in the near future. North is up.

\section{Discussion}

\subsection{Loss Tangent}

The imaginary component of the dielectric permittivity $\left(\epsilon_{\text {imag }}\right)$ describes the absorption loss of a material and is often discussed as the loss tangent $\left(\tan \delta=\epsilon_{\text {imag }} / \epsilon_{\text {real }}\right)$. Like for water, and thus wet soils, $\epsilon_{\text {imag }}$ of rocks is temperature dependent (e.g., [31-33]). Detecting lava emplacements at depth therefore is a function not only on the monitoring wavelength (SMAP $\lambda=21 \mathrm{~cm}$ ) but also on the temperature of the flow. In Figure 5, for example, we compare the absorption length $\left(d=\frac{\lambda}{2 \pi \sqrt{2\left(\left|\epsilon_{\text {real }}\right|-\epsilon_{\text {imag }}\right)}}\right)$ [34] for the bulk materials relevant to the cases presented here: basalt and seawater.

Generally, the loss tangent decreases with temperature. If the deviations from linear behavior observed at $2.45 \mathrm{GHz}$ by Hartlieb et al. [31] are also present at the $1.41 \mathrm{GHz}$ monitored by SMAP, the loss tangents of cooling lava may be indiscriminate from modestly warm surrounding rock. This may help explain why Erta Ale activity is not evident in the SMAP data. (The relative size of the lava lake with respect to the SMAP footprint size does not help; see below.) Note, however, that $\epsilon_{\text {imag }}$ is frequency dependent [35]. In Figure 5, we show the range of loss tangents for dry basalt at $1.6 \mathrm{GHz}$ from Ulaby et al. [35] for comparison.

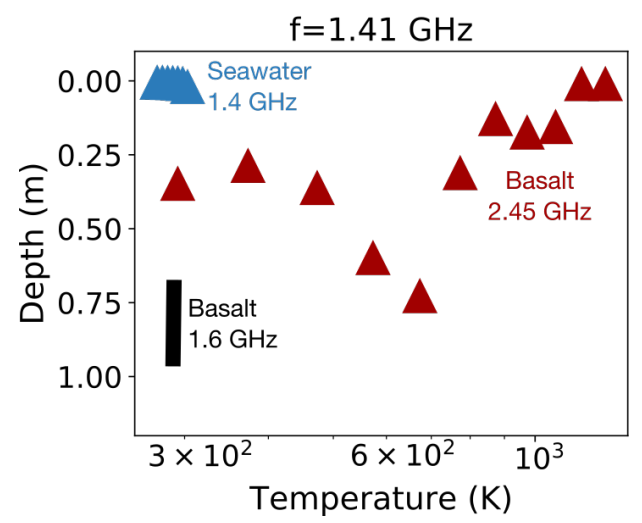

Figure 5. Absorption length at the SMAP frequency as a function of temperature for basalt rock at 1.6 GHz (black; Ulaby et al. [35]), basalt rock at $2.45 \mathrm{GHz}$ (red; Hartlieb et al. [31]), and seawater at $1.4 \mathrm{GHz}$ (blue; Lang et al. [32]). Ulaby et al. [35] values are shown for a range of porosities, which control the real (but not imaginary) component of the dielectric permittivity. Real and imaginary components of the dielectric constant used to calculate absorption length are taken from the respective citations. 
For a flow of a given initial temperature, we can compare the depth to which SMAP should be sensitive (a few wavelengths, white), the absorption length for a basalt as a function of temperature (gray line, Hartlieb et al. [31]), and the temperature profile for flows of different ages (red lines). Here temperature is shown relative to the ambient temperature, $\Delta T_{B}$, and is calculated following the formulations of Lorenz et al. [9] and Bondarenko et al. [8]. The brightness temperature in a given polarization $\left(T_{B, X}\right.$ where $\mathrm{X}=\mathrm{H}$ or $\left.\mathrm{V}\right)$ is

$$
T_{B, X}=E_{X} T_{\text {apparent }}
$$

where the Fresnel coefficient for emission off a smooth boundary is

$$
\begin{aligned}
& E_{H}=1-\left(\frac{\cos \theta-\sqrt{\epsilon-\sin ^{2} \theta}}{\cos \theta+\sqrt{\epsilon-\sin ^{2} \theta}}\right)^{2} \\
& E_{V}=1-\left(\frac{\epsilon \cos \theta-\sqrt{\epsilon-\sin ^{2} \theta}}{\cos \theta+\sqrt{\epsilon-\sin ^{2} \theta}}\right)^{2}
\end{aligned}
$$

and the apparent temperature, $T_{\text {apparent }}$ is

$$
T_{\text {apparent }}=\sec \left(\theta^{\prime}\right) \int_{0}^{\infty} \kappa \Delta T(z) e^{-\sec \theta^{\prime} \tau(z)} d z+T_{\text {ambient }}
$$

depending on temperature at depth $(T(z))$ and the flow opacity. The evolution of a radiatively cooling flow is

$$
\Delta T(z)=\left(T_{\text {lava }}-T_{\text {ambient }}\right) e^{-t k / z^{2}}
$$

where $t$ and $k$ are time and flow thermal diffusivity, respectively. The optical depth $(\tau)$ is the integral of the absorption coefficient $(\kappa)$ :

$$
\begin{aligned}
& \tau=\int_{z_{0}}^{z} \kappa d z \\
& \kappa=\frac{2 \pi \sqrt{\epsilon} \tan \delta}{\lambda}
\end{aligned}
$$

In Figure 6 we show a nominal case of a lava flow within initial temperature of $1200 \mathrm{~K}$ and surrounding temperature $297 \mathrm{~K}$ (as one might expect at Erta Ale), assuming that $\tau$ linearly increases with depth, and that the thermal diffusivity is constant $\left(4 \times 10^{-7}\right.$, Long and Wood [36]). Depending on the dielectric properties of the surface, flows $<3$ months old could show increased $T_{B}$ by $100 \mathrm{~s}$ $\mathrm{K}$; cooler flows are increasingly difficult to distinguish. If properties like the loss factor and thermal diffusivity are also functions of temperature, then the window of opportunity collapses further. The gray line in Figure 6 represents the absorption length calculated from Hartlieb et al. [31]; scenarios above this line and within the white box should be observable by SMAP. (We note that the temperature evolution calculation does not take into account latent heat; predicted cooling times therefore represent short endmembers.) For flows at lower initial temperatures, the profiles cool more quickly than shown in Figure 6, shifting to the left to make an even smaller observing window. The temperature profiles also cooling off more rapidly at depth and in time if we instead assume a constant loss tangent (i.e., $\tau$ is constant with depth). Thus, the thermal properties of the flow, and their relation to the absorptive properties of the rock, control whether a flow will be discernible at depth. 


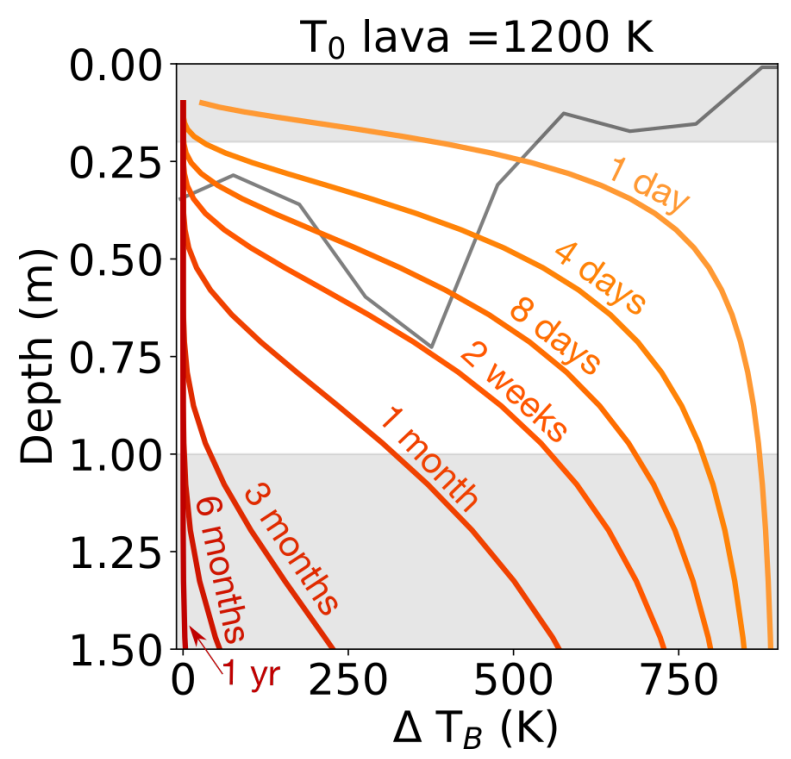

Figure 6. Temperature profile of a basalt flow as a function of depth for different flow ages. Observability of a flow is a confluence of the depths to which SMAP is sensitive (a few wavelengths; white box), the age of the flow (reds), and absorptivity of the flow (approximated by the gray line from the $2.45 \mathrm{~Hz}$ measurements of Hartlieb et al. [31]).

\subsection{Areal Fraction}

The extreme dielectric contrast between water and dry rock (be it soil, sand, or bulk deposits) is clearly discernible in SMAP data: in Figure 3, water-dominated gridded elements have brightness temperatures $100 \mathrm{~K}$ lower than land-dominated pixels. As many of the volcanoes on Earth are found on islands and along coastlines, the Kilauea Lower East Rift Zone is not the only scenario that might be affected. To explore how, we model the temperature profiles of cooling lava flows as described above and mix the resulting brightness temperatures with those typical of sea (50-100 K) and land (260-300 K) in SMAP data via

$$
T_{B}=f T_{B, \text { lava }}+(1-f) T_{B, o t h e r}
$$

where $f$ is the fraction of a footprint that the lava occupies. In Figure 7, we compare difference between mixed $T_{B}$ and typical surroundings and find that the thermal anomalies from shallow and/or small flows quickly approach the background temperature of a water- or land-dominated grid element within the time between SMAP observations (8 days). Unsurprisingly, thicker, younger, larger flows are easiest to identify in both sea and land scenarios. The contrast between fresh flows and sea water may actually facilitate observation, as even relatively small flows have $\Delta T_{B}$ much greater than the expected variation (e.g., diurnal) in SMAP observations (which is greater than SMAP's temperature resolution on the order of a few $\mathrm{K}$ ).

For the specific case of Kilauea, the maximum peaks in observed brightness temperature (shown in Figure 3) are on the order of $100 \mathrm{~K}$ above the scene normal, shown in Figure 7 as a black line. At the end of the 2018 activity, the maximum areal fraction (relative to the $9 \mathrm{~km}$ grid) was 0.43 , which could be observable if SMAP observations penetrate $1 \mathrm{~m}$ deep into the flow, but note that this simple model optimistically assumes the entire lava-covering area is a uniform temperature. If the temperature anomalies observed in June (minimal area coverage) and August (cooling flows) are due to volcanic activity, then the lack of July observations (peak activity) would require an unlucky confluence of eruption timing relative to SMAP observation and insufficient volumes. Thus, even at the finer spatial scales afforded by resampling, the Kilauea flow did not reach sufficient extent to be detectable in SMAP data. 

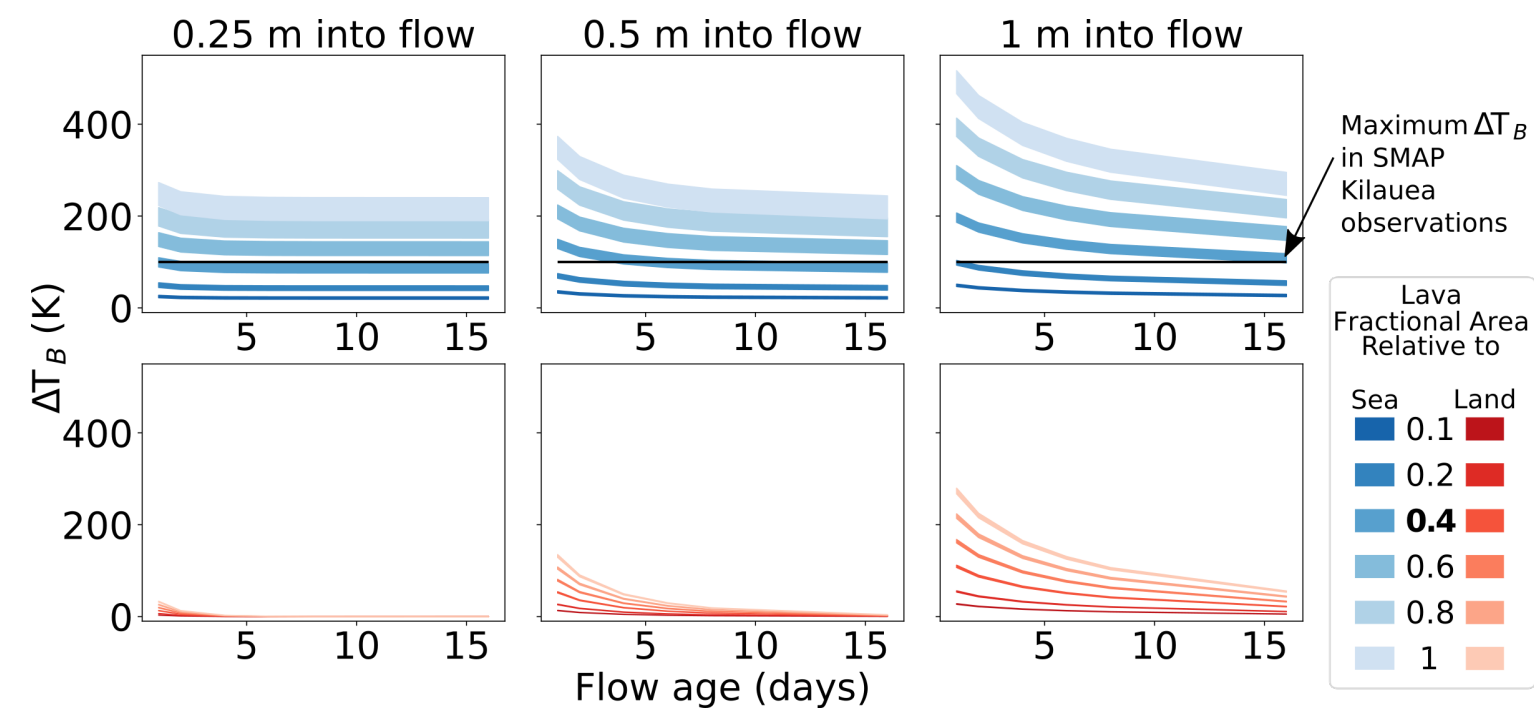

Figure 7. Change in brightness temperature for cooling lava flows as a function of fractional area in a footprint where the surrounding is sea (blues) or land (reds). Line thickness represents the range of possible differences between a lava flow and typical brightness values for sea and land (50-100 K and 280-320 K) in SMAP data. The 0.4 fractional area curves represent the maximum extent of the Kilauea flow field.

\section{Conclusions}

We have examined three cases of SMAP observations of volcanic eruptions and found that the practical upper limit of detectability is higher than expected from first principles. To date, unambiguous detection of volcanic activity with the SMAP passive radiometer has been frustrated by several (sometimes compounding) factors, including the size of the flow relative to the observation scale and the age of the flow relative to the depths probed by the sensor and/or allowed by the loss tangent of the lava.

Based on these observations and our thermal modeling, shallow flows of any area are unlikely to be detectable by SMAP if surrounded by warm land (e.g., desert locations like Erta Ale) as the predicted temperature excesses are not high enough to be distinct from natural diurnal variation $(60 \mathrm{~K})$. Thicker flows $>48 \mathrm{~km}^{2}$ should be observable within the SMAP observation window. Along the shore, thicker flows are increasingly easier to observe, especially if the areal extent of the emplacement is $>32 \mathrm{~km}^{2}$ (typically $\Delta 30 \mathrm{~K}$ variations for sea surfaces seen in Figure 3). Notably, while the cumulative Kilauea flow reached this extent, parts of the flow had already cooled (Figure 2). Continued monitoring for peak $T_{B}$ signals in SMAP observations is therefore warranted should large eruptions occur during SMAP's operation. For instance, SMAP would have had better chances observing the Laki eruptions of 1783-1784: a series of flows totaling $100 \mathrm{~km}^{2}$ which were emplaced over one particular month [37], maximizing both areal extent and heat at SMAP-penetrating depths.

On Venus, cooling rates are slower relative to Earth despite the thicker atmosphere because the absorption and re-radiation of $\mathrm{CO}_{2}$ in the boundary layer makes convection an inefficient heat loss mechanism [38]. Venusian flows thus extend much further from their sources than terrestrial counterparts. Flows with typical areas $<10^{2} \mathrm{~km}^{2}$ to $>10^{4} \mathrm{~km}^{2}$ associated with small edifices or coronae, respectively, have been mapped in Magellan data [39]. However, because the emplacement rate of these flows is not well understood, the area of a single event is ill constrained. Employing the terrestrial analog employed by Lorenz et al. [9] where typical events are $75 \mathrm{~km}^{2}$ and the thermal evolution model presented here (conservative for Venus), we find that the increased resolution of the radiometer observations planned with EnVision's VenSAR ( $4.5 \mathrm{~km}$ azimuth, $38 \mathrm{~km}$ range) may counteract the smaller penetration depth at $3.2 \mathrm{GHz}(9.4 \mathrm{~cm})$. The maximum temperature excess for a flow of this 
size remains $>20 \mathrm{~K}$ for 40 days at $18 \mathrm{~cm}$ depth but not at $9 \mathrm{~cm}$. Thus, as expected from our SMAP observations, penetration depth will control observability.

Other complicating factors discovered in this investigation will be less of a concern on other worlds. Natural RFI occurrences should be quiescent relative to the rate of anthropogenic sources here on Earth. More laboratory studies of the temperature dependence of the loss tangent of rock types at shorter frequencies are necessary to elucidate whether the behavior affects observation.

Author Contributions: Conceptualization, R.D.L.; methodology, R.D.L. and S.M.M.; software, S.M.M.; validation, S.M.M.; formal analysis, S.M.M.; investigation, S.M.M.; resources, R.D.L. and S.M.M.; data curation, S.M.M.; writing-original draft preparation, S.M.M.; writing-review and editing, R.D.L. and S.M.M.; visualization, S.M.M.; supervision, R.D.L.; project administration, R.D.L.; funding acquisition, R.D.L. All authors have read and agreed to the published version of the manuscript.

Funding: This research was funded by NASA grant number NNX16AN36G to RDL.

Conflicts of Interest: The authors declare no conflict of interest.

\section{References}

1. Thomas, R.J.; Rothery, D.A. Volcanism on Mercury. Elements 2019, 15, 27-32. doi:10.2138/gselements.15.1.27. [CrossRef]

2. Moore, J.M.; McKinnon, W.B.; Spencer, J.R.; Howard, A.D.; Schenk, P.M.; Beyer, R.A.; Nimmo, F.; Singer, K.N.; Umurhan, O.M.; White, O.L.; et al. The Geology of Pluto and Charon through the Eyes of New Horizons. Science 2016, 351, 1284-1293. [CrossRef] [PubMed]

3. Tobie, G.; Lunine, J.I.; Sotin, C. Episodic Outgassing as the Origin of Atmospheric Methane on Titan. Nature 2006, 440, 61. [CrossRef]

4. Thordarson, T.; Self, S. Atmospheric and Environmental Effects of the 1783-1784 Laki Eruption: A Review and Reassessment. J. Geophys. Res. Atmos. 2003, 108, AAC 7-1-AAC 7-29. [CrossRef]

5. Lorenz, R.D. Exploring Planetary Climate: A History of Scientific Discovery on Earth, Mars, Venus and Titan; Cambridge University Press: Cambridge, UK, 2019.

6. Hashimoto, G.L.; Imamura, T. Elucidating the Rate of Volcanism on Venus: Detection of Lava Eruptions Using near-Infrared Observations. Icarus 2001, 154, 239-243. [CrossRef]

7. Mueller, N.T.; Smrekar, S.; Helbert, J.; Stofan, E.; Piccioni, G.; Drossart, P. Search for Active Lava Flows with VIRTIS on Venus Express. J. Geophys. Res. Planets 2017, 122, 1021-1045. [CrossRef]

8. Bondarenko, N.; Head, J.; Ivanov, M. Present-Day Volcanism on Venus: Evidence from Microwave Radiometry. Geophys. Res. Lett. 2010, 37. [CrossRef]

9. Lorenz, R.D.; Le Gall, A.; Janssen, M.A. Detecting Volcanism on Titan and Venus with Microwave Radiometry. Icarus 2016, 270, 30-36. [CrossRef]

10. Lorenz, R.D.; MacKenzie, Shannon, M. Nontraditional Observations with the SMAP Radiometer. J. Eng. Res. Appl. 2019, 9, 13-19.

11. Elachi, C.; Allison, M.; Borgarelli, L.; Encrenaz, P.; Im, E.; Janssen, M.; Johnson, W.; Kirk, R.L.; Lorenz, R.; Lunine, J.; et al. Radar: The Cassini Titan radar mapper. In The Cassini-Huygens Mission; Springer: Berlin/Heidelberg, Germany, 2004; pp. 71-110.

12. Saunders, R.; Pettengill, G.; Arvidson, R.; Sjogren, W.; Johnson, W.; Pieri, L. The Magellan Venus radar mapping mission. J. Geophys. Res. Solid Earth 1990, 95, 8339-8355. [CrossRef]

13. Ghail, R.C.; Hall, D.; Mason, P.J.; Herrick, R.R.; Carter, L.M.; Williams, E. VenSAR on EnVision: Taking earth observation radar to Venus. Int. J. Appl. Earth Obs. Geoinf. 2018, 64, 365-376. [CrossRef]

14. Entekhabi, D.; Njoku, E.G.; O’Neill, P.E.; Kellogg, K.H.; Crow, W.T.; Edelstein, W.N.; Entin, J.K.; Goodman, S.D.; Jackson, T.J.; Johnson, J.; et al. The Soil Moisture Active Passive (SMAP) Mission. Proc. IEEE 2010, 98, 704-716. [CrossRef]

15. Chaubell, J.; Chan, S.; Dunbar, R.S.; Peng, J.; Yueh, S. SMAP Enhanced L1C Radiometer Half-Orbit 9 km EASE-Grid Brightness Temperatures; Version 2; NASA National Snow and Ice Data Center Distributed Active Archive Center: Boulder, CO, USA, 2018; doi:10.5067/0DGGEWUC6MLY. [CrossRef]

16. Touati, C.; Ratsimbazafy, T.; Ludwig, R.; Bernier, M. New Approaches for Removing the Effect of Water Damping on SMAP Freeze/Thaw Mapping. Can. J. Remote Sens. 2019, 45, 405-422. [CrossRef] 
17. Wright, R. MODVOLC: 14 Years of Autonomous Observations of Effusive Volcanism from Space. Geol. Soc. Lond. Spec. Publ. 2016, 426, 23-53. [CrossRef]

18. Coppola, D.; Laiolo, M.; Delle Donne, D.; Ripepe, M.; Cigolini, C. Hot-Spot Detection and Characterization of Strombolian Activity from MODIS Infrared Data. Int. J. Remote Sens. 2014, 35, 3403-3426. [CrossRef]

19. Spampinato, L.; Oppenheimer, C.; Calvari, S.; Cannata, A.; Montalto, P. Lava lake surface characterization by thermal imaging: Erta'Ale volcano (Ethiopia). Geochem. Geophys. Geosystems 2008, 9. [CrossRef]

20. Barberi, F.; Varet, J. The Erta Ale Volcanic Range (Danakil Depression, Northern Afar, Ethiopia). Bull. Volcanol. 1970, 34, 848-917. [CrossRef]

21. Guern, F.L.; Carbonnelle, J.; Tazieff, H. Erta'ale Lava Lake: Heat and Gas Transfer to the Atmosphere. J. Volcanol. Geotherm. Res. 1979, 6, 27-48. [CrossRef]

22. Radebaugh, J.; McEwen, A.S.; Milazzo, M.P.; Keszthelyi, L.P.; Davies, A.G.; Turtle, E.P.; Dawson, D.D. Observations and Temperatures of Io's Pele Patera from Cassini and Galileo Spacecraft Images. Icarus 2004, 169, 65-79. [CrossRef]

23. Davies, A.G.; Keszthelyi, L.; McEwen, A.S. Estimating Eruption Temperature from Thermal Emission Spectra of Lava Fountain Activity in the Erta'Ale (Ethiopia) Volcano Lava Lake: Implications for Observing Io's Volcanoes. Geophys. Res. Lett. 2011, 38. [CrossRef]

24. Global Volcanism Program. Report on Erta Ale (Ethiopia); Bulletin of the Global Volcanism Network; Smithsonian Institution: Washington, DC, USA, 2017; Volume 42. [CrossRef]

25. Global Volcanism Program. Report on Erta Ale (Ethiopia); Bulletin of the Global Volcanism Network; Smithsonian Institution: Washington, DC, USA, 2018, Volume 43. [CrossRef]

26. Global Volcanism Program. Report on Kilauea (United States); Bulletin of the Global Volcanism Network; Smithsonian Institution: Washington, DC, USA, 2019, Volume 44. [CrossRef]

27. Neal, C.A.; Brantley, S.R.; Antolik, L.; Babb, J.L.; Burgess, M.; Calles, K.; Cappos, M.; Chang, J.C.; Conway, S.; Desmither, L.; et al. The 2018 Rift Eruption and Summit Collapse of Kīlauea Volcano. Science 2019, 363, 367-374. [CrossRef] [PubMed]

28. Naismith, A.K.; Matthew Watson, I.; Chigna, G.; Thomas, H.; Coppola, D.; Chun, C. Eruption Frequency Patterns through Time for the Current (1999-2018) Activity Cycle at Volcán de Fuego Derived from Remote Sensing Data: Evidence for an Accelerating Cycle of Explosive Paroxysms and Potential Implications of Eruptive Activity. J. Volcanol. Geotherm. Res. 2019, 371, 206-219. [CrossRef]

29. Global Volcanism Program. Report on Fuego (Guatemala); Bulletin of the Global Volcanism Network; Smithsonian Institution: Washington, DC, USA, 2018.

30. Mohammed, P.N.; Aksoy, M.; Piepmeier, J.R.; Johnson, J.T.; Bringer, A. SMAP L-Band Microwave Radiometer: RFI Mitigation Prelaunch Analysis and First Year On-Orbit Observations. IEEE Trans. Geosci. Remote Sens. 2016, 54, 6035-6047. [CrossRef]

31. Hartlieb, P.; Toifl, M.; Kuchar, F.; Meisels, R.; Antretter, T. Thermo-Physical Properties of Selected Hard Rocks and Their Relation to Microwave-Assisted Comminution. Miner. Eng. 2016, 91, 34-41. [CrossRef]

32. Lang, R.; Zhou, Y.; Utku, C.; Vine, D.L. Accurate Measurements of the Dielectric Constant of Seawater at L Band. Radio Sci. 2016, 51, 2-24. [CrossRef]

33. Park, C.H.; Behrendt, A.; LeDrew, E.; Wulfmeyer, V. New Approach for Calculating the Effective Dielectric Constant of the Moist Soil for Microwaves. Remote Sens. 2017, 9, 732. [CrossRef]

34. Campbell, M.J.; Ulrichs, J. Electrical Properties of Rocks and Their Significance for Lunar Radar Observations. J. Geophys. Res. 1969, 74, 5867-5881. [CrossRef]

35. Ulaby, F.; Bengal, T.; Dobson, M.; East, J.; Garvin, J.; Evans, D. Microwave Dielectric Properties of Dry Rocks. IEEE Trans. Geosci. Remote Sens. 1990, 28, 325-336. [CrossRef]

36. Long, P.E.; Wood, B.J. Structures, Textures, and Cooling Histories of Columbia River Basalt Flows. Geol. Soc. Am. Bull. 1986, 97, 1144-1155. [CrossRef]

37. Thordarson, T.; Self, S.; Óskarsson, N.; Hulsebosch, T. Sulfur, Chlorine, and Fluorine Degassing and Atmospheric Loading by the 1783-1784 AD Laki (Skaftár Fires) Eruption in Iceland. Bull. Volcanol. 1996, 58, 205-225. [CrossRef] 
38. Snyder, D. Cooling of Lava Flows on Venus: The Coupling of Radiative and Convective Heat Transfer. J. Geophys. Res. Planets 2002, 107, 10-1-10-8. [CrossRef]

39. Stofan, E.R.; Brian, A.W.; Guest, J.E. Resurfacing Styles and Rates on Venus: Assessment of 18 Venusian Quadrangles. Icarus 2005, 173, 312-321. [CrossRef]

(C) 2020 by the authors. Licensee MDPI, Basel, Switzerland. This article is an open access article distributed under the terms and conditions of the Creative Commons Attribution (CC BY) license (http:/ / creativecommons.org/licenses/by/4.0/). 